\title{
Papillary Eccrine Adenoma
}

National Cancer Institute

\section{Source}

National Cancer Institute. Papillary Eccrine Adenoma. NCI Thesaurus. Code C4173.

A benign neoplasm arising from the sweat glands. It is characterized by the presence of eccrine ducts in the dermis containing intraluminal papillary projections. 